\title{
Recyclability Process of Gypsum Reinforced with Hemp Fabrics: Impact and Flexural Behaviour
}

Luca Boccarusso, Davide Mocerino, Massimo Durante, Fabio Iucolano, Fabrizio Memola Capece Minutolo and Antonio Langella

\author{
Luca Boccarusso. Department of Chemical Materials and Production Engineering, University of Naples Federico II, Italy \\ Corresponding author: luca.boccarusso@unina.it \\ Davide Mocerino. Department of Chemical Materials and Production Engineering, University of Naples Federico II, Italy \\ Massimo Durante. Department of Chemical Materials and Production Engineering, University of Naples Federico II, Italy \\ Fabio Iucolano. Department of Chemical Materials and Production Engineering, University of Naples Federico II, Italy \\ Fabrizio Memola Capece Minutolo. Department of Chemical Materials and Production Engineering, University of Naples \\ Federico II, Italy
}

Antonio Langella. Department of Chemical Materials and Production Engineering, University of Naples Federico II, Italy

\begin{abstract}
Gypsum is an ancient material, still widely used and suitable for many applications in the constructions due to its low cost, availability, lightweight, good thermal and sound isolating behaviour, fire resistance and low energy consumption. One of the most established application is its use as building walls and as pointed out in authors previous research works, it can be very useful and interesting to reinforce the gypsum with vegetable fibres like hemp. This aspect is in line with the current world situation where every industrial company needs to decrease the materials waste, increase recyclability and use more eco-friendly materials. Therefore, this work aims at designing, manufacturing, and testing of both commercial and recycled gypsum specimens reinforced with hemp fabrics, in order to improve impact and flexural resistance of traditional gypsum boards. The recycling process was carefully studied to detect the best grinding time, temperature and time of the heat treatment required to allow the reutilization of gypsum powders. Three point bending and impact tests at different energy levels were carried out in order to understand how the presence of the hemp fabrics within the gypsum matrix and how the recycling process affect the mechanical response of reinforced gypsum.
\end{abstract}

Keywords. Gypsum, Hemp, Recyclability, Impact, Bending

\section{Introduction}

Gypsum is one of the earliest building materials and its application history can be traced back to 4000 years ago [1-3]. Its easy fabrication, low energy consumption and price, good aesthetic appearance, good fire resistance, good recyclability, good sound and thermal isolation properties, make gypsum one of the most important construction materials used in house building applications and often it is preferable to other building materials (wood, plywood, etc.) [4-6]. Contrary to these advantages, gypsum is not characterized by high mechanical properties especially when impact and flexural loads, whose occurrence is very likely for building structures, are considered. This represents a limiting factor in the use of gypsum as structural material making necessary the improvement of its mechanical strength in order to extend its applications.

In order to overcome these limitations, the most established and widespread way for gypsum's manufacture companies is to reinforce the gypsums with a reinforcement phase, usually glass fibers [7]. Several studies showed indeed that glass fibre reinforced plaster materials possess appreciable toughness values $[6,8]$ but it is important to highlight that the high cost of glass fibres represents a handicap for their association with a cheap material like gypsum and noteworthy is that the use of glass fibres is not in line with the global request for reducing the environmental impact of products also considering that the use of glass fibres as reinforcement can involve workers' health problems during manufacturing, recycling or during the lifetime after an accidental breaking [9]. 
Recyclability Process of Gypsum Reinforced with Hemp Fabrics: Impact and Flexural Behav...

Therefore, going to a sustainable environmental perspective, a possible solution is the use of natural fibers instead of glass as reinforcement. On this point, several researchers focused their attention. For instance, Oliveres et al. [10] reinforced gypsum with cork granules studying its acoustic absorption, thermal conductivity and mechanical properties achieving very interesting results. Li et al. [11] addressed treating cotton stalk fibre surface with styrene acrylic emulsion to improve the interfacial combined state of cotton stalk fibre/gypsum composite, obtaining a notably increasing of mechanical properties in terms of flexural strength and modulus. Iucolano et al. [12] studied the possibility to reinforce gypsum using abaca fibers proving that if the fibers were properly washed with distilled water an improvement of the flexural strength was achieved.

Among several type of vegetable fibers that can be used as reinforcement, hemp fiber is one of the most interesting and it is receiving an increasing of attention in the last years due to its high mechanical properties, low density and cost and the high cellulose content (i.e. 70-74\%) [13] that make it suitable as reinforcement phase. This was highlighted in several papers [14-16] and in some case it was pointed out that hemp can replace the well know and used glass fibres. Indeed, Iucolano et al. [7] proved that in terms of flexural strength and impact resistance, short hemp fibers can be considered as a suitable replacing of glass fibers to reinforce gypsum.

Going in the greenest direction manufacturing, a product should be constituted from natural components as well as be recyclable. In this context gypsum reinforced by hemp fibers appears to be a valid material, indeed its constituents derived from natural original and the gypsum matrix leads itself well to be recycled: the dihydrate and hemihydrates phases of calcium sulfate can be converted into each other under certain conditions, which provides a basic theory for the recycling of waste gypsum [2,5].

Aiming to produce a gypsum product usable for building walls with enounced flexural and impact resistance using vegetable fibers as reinforcement and ensuring in the same time the recyclability of gypsum at the end life of products, this work aims to study the possibility to reinforce gypsum with hemp fabrics evaluating the possibility to recycle the gypsum by using an ad hoc recycling process.

\section{Materials and methods}

\subsection{Materials}

The gypsum used in this investigation was purchased from Gyproc Saint-Gobain (Milano, Italy) and it is mainly constituted by calcium sulphate hemihydrate. The hemp fibers were purchased from Fidia Srl (San Mariano di Corciano, Italy) in form of fabric with an areal weight density (GMS) of $380 \mathrm{~g} / \mathrm{m}^{2}$.

\subsection{Sample production and testing}

The dry gypsum mixture was homogenized, added to the distilled water and mixed for about 30s; according to data sheet the water to gypsum weight ratio was equal to 0.7 . The mixture and the hemp fabrics was casted into prismatic open moulds $\left(100 \times 100 \times 16 \mathrm{~mm}^{3}\right.$ and $160 \times 40 \times 16 \mathrm{~mm}^{3}$ ) for producing different sample types for impact and bending tests, respectively. For each typology, the gypsum was reinforced with $4.0 \mathrm{wt}$ \% of hemp fibers. In Fig. 1, a schematization of the molds adopted for samples production is illustrated. In order to avoid fabric reinforcement distortion during the gypsum casting, at first the hemp fabrics were fixed in a stretching frame which was kept in the mold during the casting operation and drying phase. 
a)

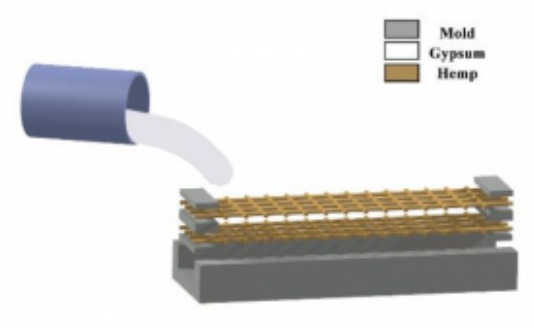

b)

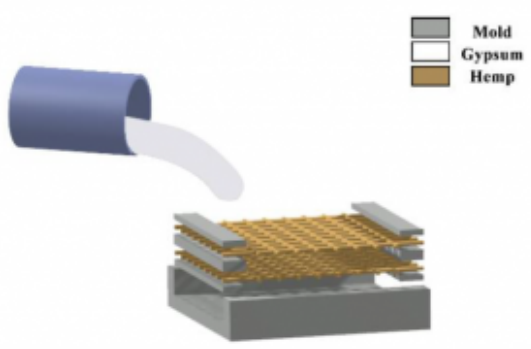

Fig. 1. Schematization of the mould adopted for the production of flexural (a) and impact (b) samples.

The water-gypsum mixture together with the hemp fabrics were compacted in the mould with a conventional vibration table for about $30 \mathrm{~s}$. The compacted mixture exhibited a setting time of about $20 \mathrm{~min}$ and after $2 \mathrm{~h}$ from it, the specimens were demolded, dried for $48 \mathrm{~h}$ at $\mathrm{T}=40{ }^{\circ} \mathrm{C}$ and finally stored in a climatic chamber (MSL Humichamber, mod. EC 125 ) at $20^{\circ} \mathrm{C}$ and $\mathrm{RH}=50 \%$, until the time of testing.

Bending tests were carried out in three-point bending test configuration (Fig.2a), by using an universal testing machine (MTS Aliance RT/50) according to the experimental procedure elsewhere reported [7,9]. In particular, the span length was fixed at $100 \mathrm{~mm}$ and a deflection rate of $1.0 \mathrm{~mm} / \mathrm{min}$ was adopted. Three specimens were manufactured and tested and the flexural stress $\left(\sigma_{f}\right)$, strain $\left(\varepsilon_{f}\right)$ and flexural modulus $\left(E_{f}\right)$ were evaluated according to equations $(1-3)$ respectively, where $L$ is the span length, $b$ the width, $d$ the depth, $f$ the maximum deflection, $F$ the applied load and $m$ the slope of the tangent to the initial straight-line portion of the load-deflection curve.

$$
\begin{aligned}
& \sigma=\frac{3 F L}{2 b d^{2}} \\
& \varepsilon=\frac{6 f d}{L^{2}} \\
& E=\frac{m L^{3}}{4 b d^{3}}
\end{aligned}
$$

Regarding the impact tests, penetration tests were carried out by using a falling weight machine (Ceast Instron Fractovis). In particular, penetration tests $\left(E_{i}=40 \mathrm{~J}\right)$ were carried out in order to evaluate the overall effect of the presence of the fiber reinforced samples over the unreinforced gypsum. Specimens $100 \times 100 \times 16 \mathrm{~mm} 3$ were centrally loaded by an instrumented cylindrical impactor with a hemispherical nose 19,8 $\mathrm{mm}$ in diameter and a total mass of $3.64 \mathrm{~kg}$ (Fig.2b). The impactor was instrumented to record the force values that allowed to draw the load-displacement curve and to evaluate the absorbed energy after the impact $[9,17]$. As before, three specimens for each energy level were manufactured and tested. 
a)

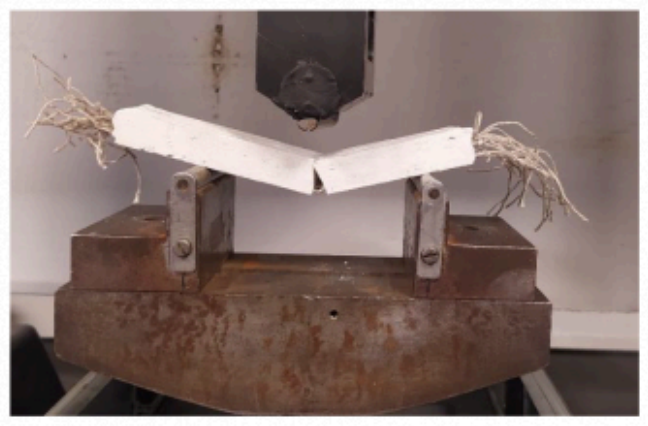

b)

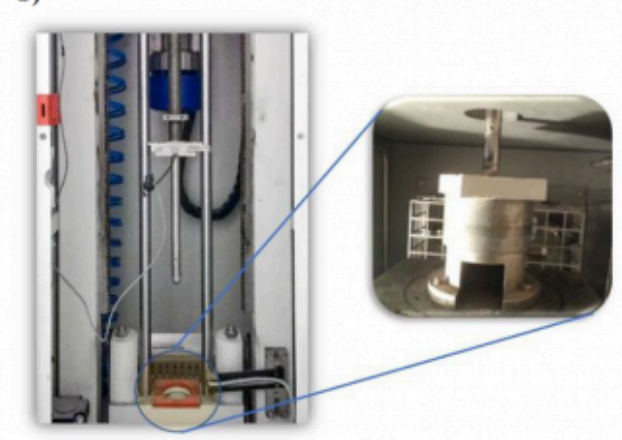

Fig. 2. Set up of (a) three point bending and (b) impact tests.

\subsection{Gypsum recycling phase}

After tests, the hemp fabrics were extracted, and the pieces of gypsum were recovered and subjected to grinding by using a commercial blender with a grinding velocity of $30000 \mathrm{rpm}$ and a time of 3 minutes. These parameters were chosen according to what established in authors' previous research work [2].

In order to use a gypsum mixture with the adequate value of granulometry, the granulometry of the grinded gypsum powder was controlled by using 1000-500-250-125 and $50 \mu \mathrm{m}$ sieves, so the obtained granulometry curve was compared with the one of supplied gypsum. Finally, in order to convert the dihydrate phase into the hemihydrates phases of calcium sulfate (i.e. allow the recycling of gypsum) an heat treatment is required. Then by using the climatic chamber (MSL Humichamber, mod. EC 125) a temperature of $140^{\circ} \mathrm{C}$ for 1 hour was adopted for the heat treatment. Also these parameters were chosen according to what established in authors' previous research work [2]. Therefore, thermogravimetric analyses (TG, Netzsch, model 409ST Luxx) were carried out in order to confirm that the heat treatment conditions allow to convert the dihydrate phase into the hemihydrates phases of calcium sulfate. After the heat treatment, the gypsum powder is ready to be used for the production of a recycled samples following the procedure described in section 2.2. In the present work, one recycle was carried out and for each recycle new hemp fabrics were adopted.

\section{Results and discussion}

After the production and testing of both unreinforced and reinforced gypsum samples, broken pieces of gypsum were grinded according to the procedure explained in the previous section. The cumulative granulometry curves of both supplied and grinded gypsum are plotted in Fig.3a where the good result is clearly highlighted. After grinding, the powders undergone the described heat treatment and in Figs.3b and c the results of the thermogravimetric analyses were reported. In detail, in Fig. 3b a comparison between the supplied gypsum and grinded gypsum before the thermal treatment, i.e. dihydrate gypsum, is reported. The supplied gypsum (red curve) has a moderate weight loss (less than $6 \%$ ) and a single peak of the dTG, related to decomposition (water loss) of the "hemi-hydrate gypsum" phase in "anhydrous gypsum". Hemihydrates phase, is the most reactive phase with water, and it is therefore the lost abundant phase typically found in commercial plaster.

Differently, the sample of hydrated gypsum (green curve) showed more weight loss (around 20\%) and two peaks of dTG, the first concerning the decomposition of calcium sulphate dihydrate into hemihydrates $\left(\mathrm{T} \approx 130^{\circ} \mathrm{C}\right)$ and the 
second related to the decomposition of the hemihydrate in anhydrous phase $\left(\mathrm{T} \approx 150{ }^{\circ} \mathrm{C}\right)$. In Fig. $3 \mathrm{c}$, the results of the thermogravimetry analyses for the gypsum before and after the heat treatment conditions are reported; the good results are clearly evident since the curves are very close to each other.

a)

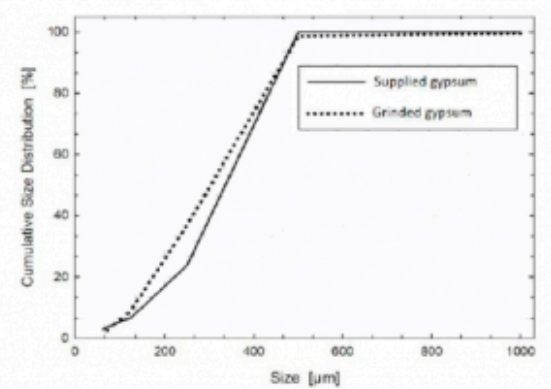

b)

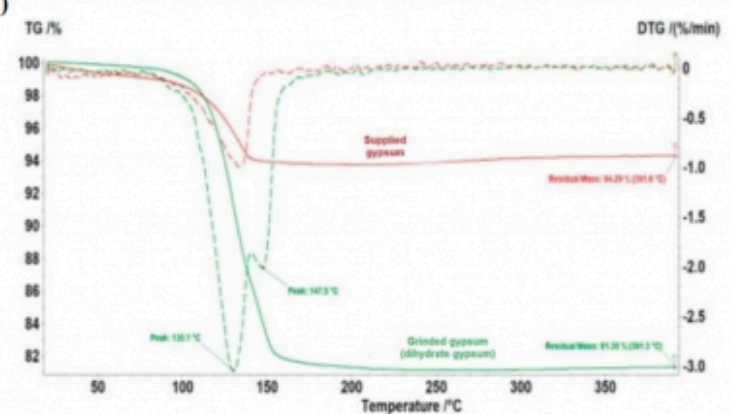

c)

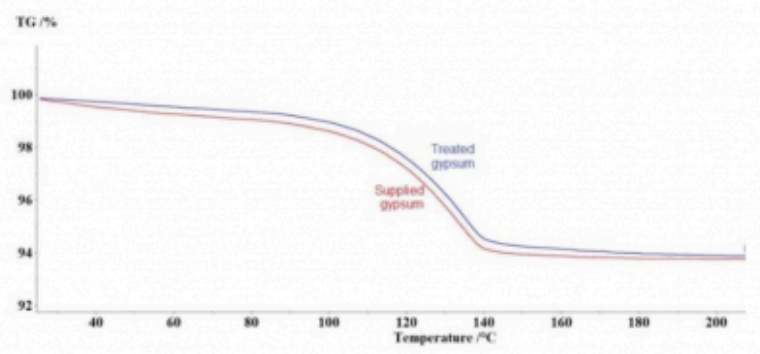

Fig. 3. (a) Cumulative size distribution of supplied and grinded gypsum; (b) thermogravimetric curves of supplied and grinded gypsum and (c) of heat treated gypsum.

In Fig. 4 the results of the bending (Fig.4a) and impact tests (Fig.4b) for supplied (labelled as Reference) and recycled gypsum (labelled as Recycled) were plotted reporting the typical curves for each sample typology.

From the tests appeared that the flexural strength was not affected so much from the recycling process, indeed the maximum strength reduction was of about $10 \%$ and for the elastic modulus of about $25 \%$.

The impact tests showed that the impact properties are more affected from the recycling process, indeed a reduction up to the $50 \%$ of the peak load and of $25 \%$ of the adsorbed energy respect to supplied gypsum was detected.

Looking at Figs. 5 and 6, the effect of the presence of the hemp reinforcing are clearly highlighted. In detail, in Fig.5a it is possible to observe the differences at bending between the reference gypsum samples and the reinforced one. The former exhibits the typical brittle behavior of a ceramic material, i.e. after the reaching of the maximum stress of around 3.0 MPa, a sudden stress drop occurred. When gypsum was reinforced with hemp fibers, an evident difference can be noted looking at the post-cracking behavior; indeed all fiber-reinforced composites show a kind of ductile behavior. 
a)

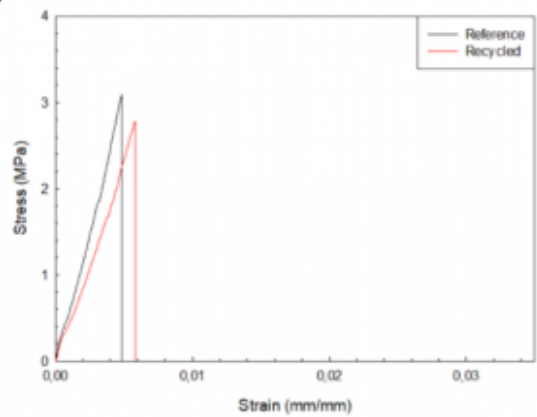

b)

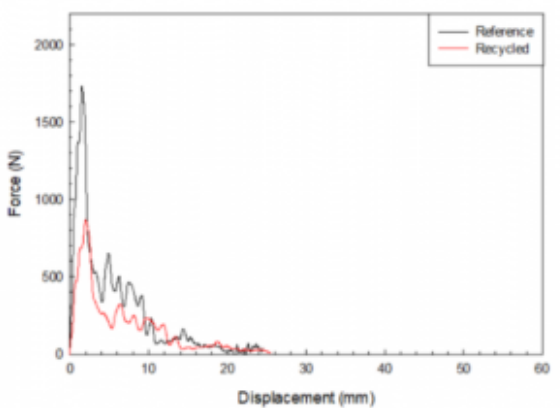

Fig. 4. (a) Typical stress-strain curves carried out from bending tests for supplied and recycled gypsum; (b) typical load-displacement curves carried out from the impact tests for reference and recycled gypsum.

The stress-strain curve can be divided in two tracts: (i) the first one (up to the reaching of the first stress value peak) where the behaviour is elastic and the failure affects the gypsum matrix. (ii) the second tract that represents the post crack part of the curve, highlights the beneficial effects conferred from the presence of fibers, i.e. the recovery of stress with a ductile behavior, the remarkable improvement of the strain at breaking and the different failure mode. Indeed on this last point, respect to the un-renforced samples, in the reinforced one a fibres pull-out was observed leading to the breaking of the sample in two pieces that held together at the end of test thank to the presence of the fabric; broken fibres were not observed in any case.

Passing at the recycled samples (Fig.5b), it is possible to note how the presence of fibers relives the performances worsening of the only gypsum obtained from the recycle (Fig. 4a).

Looking at the results of the impact tests (Fig. 6a), it appears noticeable that the specimen without fibers shows a brittle behavior, with a peak of the maximum force around $1800 \mathrm{~N}$, followed by a rapid load fall with a complete fracture of the specimen. Conversely, the typical load-displacement curve of fiber-reinforced samples showed a variable trend with the presence of two force peaks with a little recovery of the load caused by the action of the fibers.

The absorbed energy mechanism is the pull out of the fibers, in fact at the end of the penetration test the gypsum matrix continues to stay anchored to the fibers (see Fig.7). The use of fibers allowed an improvement of the peak force of about $16 \%$ and of the adsorbed energy of about $320 \%$.

These effects appeared to be more evident when recycled gypsum was adopted as testified by the load-displacement curves plotted in Fig. 6b. 
a)

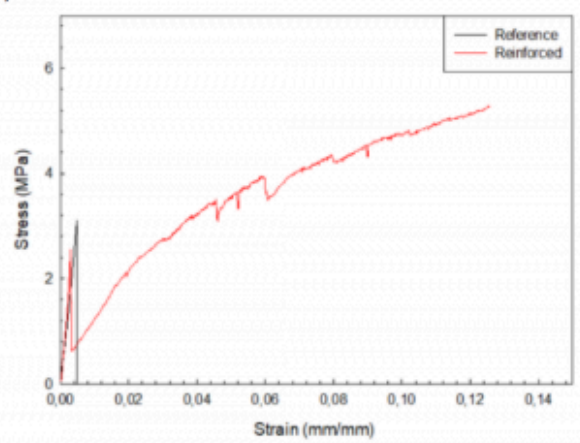

b)

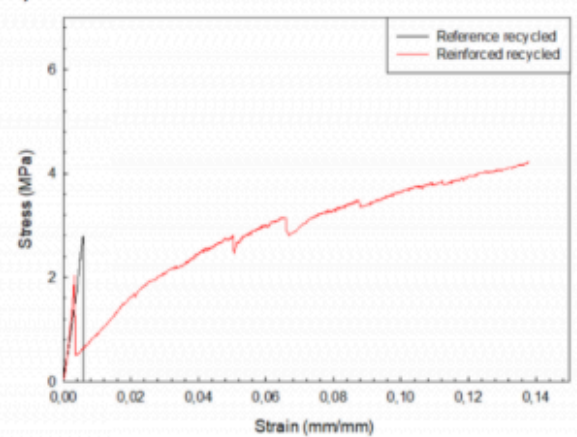

Fig. 5. Typical stress-strain curves carried out from bending tests for un-reinforced and reinforced samples using (a) reference and (b) recycled gypsum.

a)

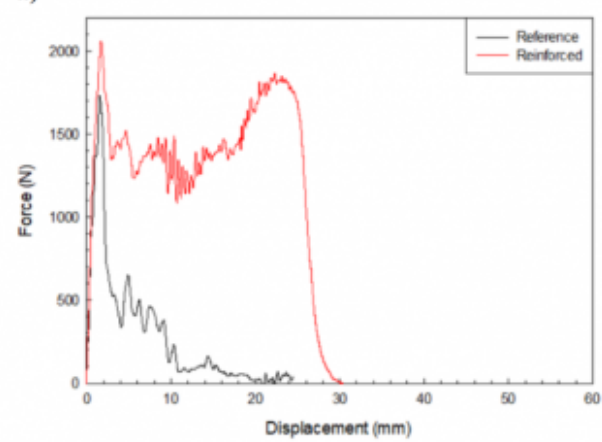

b)

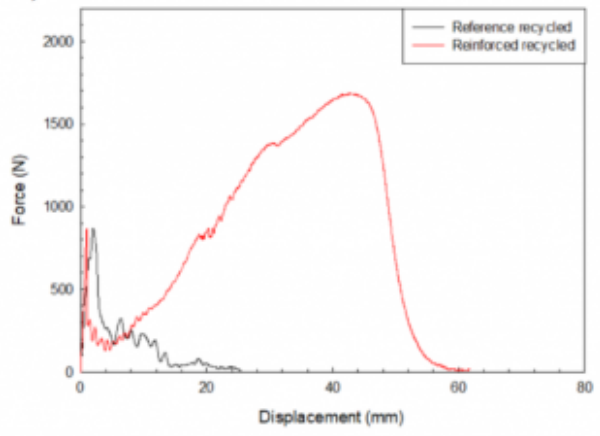

Fig. 6. Typical load-displacement curves carried out from impact tests for un-reinforced and reinforced samples using (a) reference and (b) recycled gypsum.

a)

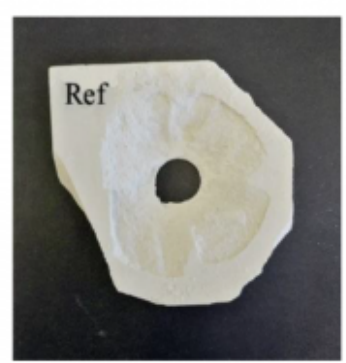

b)

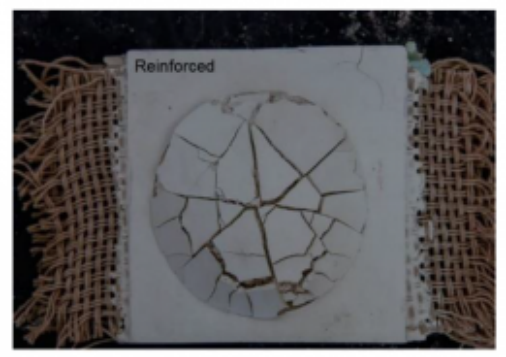

Fig. 7. Unrecycled samples: (a) typical rear side of unreinforced and (b) reinforced sample type at the end of the penetration test (40 J). 
Recyclability Process of Gypsum Reinforced with Hemp Fabrics: Impact and Flexural Behav...

\section{Conclusions}

In this work, gypsum was reinforced with hemp fabrics in order to overcome some typical limitations of gypsum, like the low impact resistance and flexural resistance and then to promote the development of a sustainable and environmentally friendly production of building materials also studying the possibility of recycling. Three-point bending tests proved that, even though the presence of fibers reduced the flexural modulus and strength, on the other hand it allowed a slight stress-strain recovery after the brittle rupture of the gypsum matrix allowed from the slipping of the fibers from the gypsum matrix during the test. More interesting results was achieved for the impact properties, indeed the impact tests highlighted that both the peak load and the adsorbed energy increased respectively of about $16 \%$ and $320 \%$ respect to gypsum only. Moving to a greener production, the possibility to recycle the tested gypsum was carefully studied. The results showed that if the recycling parameters are properly set, in terms of grinding and heat treatment conditions, the gypsum can be reutilized. If on one hand the flexural properties were not negatively affected so much, the impact response for the recycled gypsum showed a decreasing of the impact resistance, a reduction up to the $50 \%$ of the peak load and of $25 \%$ of the adsorbed energy was detected. However, the use of hemp fibers was proved to be possible also when recycled gypsum was used also achieving a partially mitigation of these disadvantages.

\section{Bibliography}

[1] Boccarusso, L. Candida, G. Durante, M. Iucolano, F. Langella, A. Minutolo, F. M. C. Mocerino, D. Pagnano, M. Production of GFRP air pipes using lightweight gypsum patterns removable in a recyclable way. AIP Conference Proceedings, 2019, 2113, DOI: $10.1063 / 1.5112651$.

[2] Boccarusso, L. Durante, M. Iucolano, F. Langella, A. Minutolo, F. M. C. Mocerino, D. Recyclability process of standard and foamed gypsum. Procedia Manufacturing, 2020, 47, 743-748.

[3] Chandara, C. Azizli, K. A. M. Ahmad, Z. A. Sakai, E. Use of waste gypsum to replace natural gypsum as set retarders in portland cement. Waste Management, 2009, 29, 1675-1679.

[4] Amziane, S. Arnaud, L. Challamel, N. Bio-aggregate-based Building Materials: Applications to Hemp Concretes. Bio-aggregate-based Building Materials: Applications to Hemp Concretes, 2013, DOI: 10.1002/9781118576809.

[5] Erbs, A. Nagalli, A. Querne de Carvalho, K. Mymrin, V. Passig, F. H. Mazer, W. Properties of recycled gypsum from gypsum plasterboards and commercial gypsum throughout recycling cycles. Journal of Cleaner Production, 2018, 183, 1314-1322.

[6] Ramachandran, V. S. Paroli, R. M. Beaudoin, J. J. Delgado, A. H. Gypsum and Gypsum Products. Handbook of Thermal Analysis of Construction Materials, 2002, 449-490.

[7] Iucolano, F. Boccarusso, L. Langella, A. Hemp as eco-friendly substitute of glass fibres for gypsum reinforcement: Impact and flexural behaviour. Composites Part B: Engineering, 2019, 175, DOI: 10.1016/j.compositesb.2019.107073.

[8] Hamzaoui, R. Guessasma, S. Mecheri, B. Eshtiaghi, A. M. Bennabi, A. Microstructure and mechanical performance of modified mortar using hemp fibres and carbon nanotubes. Materials and Design, 2014, 56, 60-68.

[9] Boccarusso, L. Durante, M. Iucolano, F. Mocerino, D. Langella, A. Production of hemp-gypsum composites with enhanced flexural and impact resistance. Construction and Building Materials, 2020, 260, 120476.

[10] Hernández-Olivares, F. Bollati, M. R. Del Rio, M. Parga-Landa, B. Development of cork-gypsum composites for building applications. Construction and Building Materials, 1999, 13, 179-186. 
[11] Li, G. Yu, Y. Zhao, Z. Li, J. Li, C. Properties study of cotton stalk fiber/gypsum composite. Cement and Concrete Research, 2003, 33, 43-46.

[12] Iucolano, F. Caputo, D. Leboffe, F. Liguori, B. Mechanical behavior of plaster reinforced with abaca fibers. Construction and Building Materials, 2015, 99, 184-191.

[13] Djafari Petroudy, S. R. Physical and mechanical properties of natural fibers. Advanced High Strength Natural Fibre Composites in Construction, 2017, 59-83.

[14] Sullins, T. Pillay, S. Komus, A. Ning, H. Hemp fiber reinforced polypropylene composites: The effects of material treatments. Composites Part B: Engineering, 2017, 114, 15-22.

[15] Ruano, G. Bellomo, F. López, G. Bertuzzi, A. Nallim, L. Oller, S. Mechanical behaviour of cementitious composites reinforced with bagasse and hemp fibers. Construction and Building Materials, 2020, 240, DOI: 10.1016/ j.conbuildmat.2019.117856.

[16] Ahmad, M. A. A. Abdul Majid, M. S. Ridzuan, M. J. M. Mazlee, M. N. Gibson, A. G. Dynamic mechanical analysis and effects of moisture on mechanical properties of interwoven hemp/polyethylene terephthalate (PET) hybrid composites. Construction and Building Materials, 2018, 179, 265-276.

[17] Scarponi, C. Sarasini, F. Tirillò, J. Lampani, L. Valente, T. Gaudenzi, P. Low-velocity impact behaviour of hemp fibre reinforced bio-based epoxy laminates. Composites Part B: Engineering, 2016, 91, 162-168.

PDF automatically generated on 2021-05-20 08:34:32

Article url: https://popups.uliege.be/esaform21/index.php?id=4044

published by ULiège Library in Open Access under the terms and conditions of the CC-BY License (https://creativecommons.org/licenses/by/4.0) 